\title{
Meta-analysis of the correlation between selenium and incidence of hepatocellular carcinoma
}

\author{
Ziwei Zhang ${ }^{1}$, Mingyu $\mathrm{Bi}^{2}$, Qi Liu ${ }^{1}$, Jie Yang ${ }^{1}$, Shiwen $\mathbf{X u}^{1}$ \\ ${ }^{1}$ College of Veterinary Medicine, Northeast Agricultural University, Harbin 150030, China \\ ${ }^{2}$ Harbin Railway Public Security Bureau Police Dog Base, Harbin 150056, P. R. China \\ Correspondence to: Shiwen Xu, email: shiwenxu@neau.edu.cn
}

Keywords: hepatocellular carcinoma, selenium, correlation, meta-analysis

Received: September 12, $2016 \quad$ Accepted: October 14, $2016 \quad$ Published: October 21, 2016

\begin{abstract}
Hepatocellular carcinoma (HCC) is the most common cancer type. There is a correlation between selenium (Se) deficiency and the incidence of HCC. To clarify the effects of Se level on the risk of HCC patients, a meta-analysis was performed. A total of 9 articles published between 1994 and 2016 worldwide were selected through searching PubMed, EMBASE, web of science, Cochrane Library, Springer Link, Chinese National Knowledge Infrastructure (CNKI), and Chinese Biology Medicine (CBM), and the information were analyzed using a meta-analysis method. Heterogeneity was assessed by using the $\mathrm{I}^{2}$ index. Publication bias was evaluated by Begg's Test analysis. Pooled analysis indicated that patients with HCC had lower Se levels than the healthy controls [standardized mean difference (SMD) $=-1.08,95 \%$ confidence intercal $(\mathrm{CI})=(-0.136,-0.08), P<0.001]$. Further subgroup analysis showed this effect to be independent of the study design, race or sample collection. In conclusion, this meta-analysis suggested an inverse correlation between Se level and the risk of HCC in humans patients.
\end{abstract}

\section{INTRODUCTION}

Hepatocellular carcinoma (HCC) is the most common liver cancer worldwide. HCC is as a result of either metabolic toxins such as alcohol or aflatoxin, a viral hepatitis infection (hepatitis B or C) [1-4]. Furthermore, it has been reported that oxidative stress is a common inducement of liver diseases that excessive reactive oxygen (ROS) in body cause mutations in cancer $[5,6]$.

Micronutrients may reduce the risk of cancer, among which selenium (Se) is of particular interest $[7,8]$. Se is an essential micronutrient required for human health and has been studied for its antioxidant and anticancer properties, specifically against HCC. Se is thought to protect macromolecules and membrane lipids from oxidative damage by combating ROS $[9,10]$. The following articles affirm the relationship between Se concentration and HCC. A matched-case-control study revealed lower blood Se levels among HCC patients [11]. There is another report on the obvious correlation relationship between low Se level and HCC in Korean hepatoma patients [12]. In contrast, the following article denies the relationship between Se in liver tissues and liver cancer. No relationship was observed Se concentration and HCC incidence [13].

Several studies have investigated the relationship between Se level and HCC risk [11-21]. Yu et al. $[19,22]$ found that there was asignificant inverse correlation between the levels of blood Se and HCC risk, while others have not demonstrated this [13]. Thus, we conduct a systematic review on the relationship between Se level and HCC risk.

\section{RESULTS}

\section{Eligible studies}

With the search strategy stated before, 9 relevant records were included in our meta-analysis and data were extracted (Figure 1) [11, 12, 16, 17, 19-21, 23, 24]. Table 1 summarized the characteristics of the 9 enrolled studies. There were 6 case-control studies and 3 cohort records. Six studies were conducted among Asian and 3 among Caucasian. In 3 studies, Se status was based on analysis of serum, whereas in the remaining 5 studies, blood was the sample specimen used and in 1 study, 
Table 1: Baseline characteristics of included trials

\begin{tabular}{|c|c|c|c|c|c|c|c|c|c|c|c|c|}
\hline \multirow{2}{*}{ First author } & \multirow{2}{*}{ Year } & \multirow{2}{*}{$\begin{array}{l}\text { Study } \\
\text { design }\end{array}$} & \multirow{2}{*}{ Race } & \multirow{2}{*}{ Age } & \multirow{2}{*}{ Female } & \multirow{2}{*}{ Male } & \multirow{2}{*}{$\begin{array}{l}\text { Follow- } \\
\text { up }\end{array}$} & \multirow{2}{*}{ Collection } & \multirow{2}{*}{ Case } & \multirow{2}{*}{ Control } & \multicolumn{2}{|c|}{ Selenium concentration } \\
\hline & & & & & & & & & & & Case & Control \\
\hline Massimo Casaril & 1994 & case-control & Caucasian & $21-74$ & 6 & 17 & NA & Serum & 23 & 19 & $\begin{array}{c}78.35 \pm 19.78 \\
\mathrm{ng} / \mathrm{ml}\end{array}$ & $\begin{array}{c}96.09 \pm 22.03 \\
\mathrm{ng} / \mathrm{ml}\end{array}$ \\
\hline TE-HSIEN LIN & 1998 & case-control & Asian & $21-82$ & NA & NA & NA & blood & 51 & 19 & $106 \pm 17.7 \mu \mathrm{g} / 1$ & $126.4 \pm 10.1 \mu \mathrm{g} / 1$ \\
\hline Ming-Whei Yu & 1999 & cohort & Asian & $30-65$ & NA & NA & 4 & blood & 69 & 138 & $131.6 \pm 30.9 \mu \mathrm{g} / 1$ & $150.2 \pm 35.2 \mu \mathrm{g} / 1$ \\
\hline $\begin{array}{l}\text { Wang Chin- } \\
\text { Thin1 }\end{array}$ & 2002 & case-control & Asian & $42-69$ & NA & 51 & 2 & blood & 51 & 50 & $0.18 \pm 0.02 \mu \mathrm{g} / \mathrm{ml}$ & $0.28 \pm 0.06 \mu \mathrm{g} / \mathrm{ml}$ \\
\hline $\begin{array}{l}\text { CHING- } \\
\text { CHIANG Lin }\end{array}$ & 2006 & case-control & Asian & $35-61$ & 9 & 9 & NA & Serum & 18 & 50 & $108.5 \pm 21.8 \mu \mathrm{g} / 1$ & $129 \pm 21.5 \mu \mathrm{g} / 1$ \\
\hline In-Wook Kim & 2012 & case-control & Asian & $40-59$ & 7 & 23 & NA & Serum & 30 & 120 & $67.47 \pm 14.3 \mu \mathrm{g} / 1$ & $108.38 \pm 29.5 \mu \mathrm{g} / 1$ \\
\hline $\begin{array}{l}\text { Dominik } \\
\text { Bettinger }\end{array}$ & 2013 & case-control & Caucasian & NA & NA & 10 & NA & blood & 10 & 10 & $85 \pm 11.5 \mu \mathrm{g} / 1$ & $117.5 \pm 15.7 \mu \mathrm{g} / 1$ \\
\hline David J Hughes & 2016 & cohort & Caucasian & $25-70$ & NA & NA & 4 & blood & 107 & 108 & $\begin{array}{c}74.127 \pm 19.29 \\
\mu \mathrm{g} / \mathrm{l}\end{array}$ & $\begin{array}{c}87.309 \pm 18.582 \\
\mu \mathrm{g} / 1\end{array}$ \\
\hline Lori C.Sakoda & 2005 & cohort & Asian & NA & 12 & 154 & 8 & toenial & 166 & 394 & $3.1 \pm 0.333 \mathrm{ppm}$ & $3.5 \pm 0.45 \mathrm{ppm}$ \\
\hline
\end{tabular}

NA, not available.

toenail Se status was used. 525 cases and 908 control subjects were enrolled in our meta-analysis.

\section{Quantitative synthesis}

The result of random-effects meta-analysis showed that Se levels was inversely correlated with HCC [standardized mean difference $(\mathrm{SMD})=-1.08,95 \%$ $\mathrm{CI}=(-0.136,-0.08), P<0.001]$. The result of pool analysis showed lower Se level had a relationship with HCC with obvious heterogeneity $\left(\mathrm{I}^{2}=74.3 \%, P<0.001\right)$ (Figure 2$)$.

In the subgroup analysis by study design, a significant correlation was found in case-control study [SMD $=-1.388$, $95 \% \mathrm{CI}=(-1.751,-1.026), P<0.001]$ and cohort study
$[\mathrm{SMD}=-0.733,95 \% \mathrm{CI}=(-0.945,-0.520), P<0.001]$ (Figure 3). In the race subgroup analysis, lower Se level was also found in Caucasian $[\mathrm{SMD}=-0.918,95 \% \mathrm{CI}=(-1.443$, $-0.393), P=0.001]$ and in Asian (SMD $=-1.115,95 \%$ $\mathrm{CI}=(-1.526,-0.784), P<0.001]$ (Figure 4). In the subgroup analysis by collection, the inverse correlation between Se level and HCC were observed in serum $[\mathrm{SMD}=-1.113,95 \%$ $\mathrm{CI}=(-1.472,-0.755), P<0.001]$, blood [SMD $=-1.241$, $95 \% \mathrm{CI}=(-1.795,-0.678), P<0.001]$ and toenail $[\mathrm{SMD}=-0.889,95 \% \mathrm{CI}=(-1.081,-0.697), P<0.001]$ (Figure 5).

Publication bias was detected by Begg's test, the $P$-values was 0.348 . Therefore, we can assume there were insignificant in publication bias.

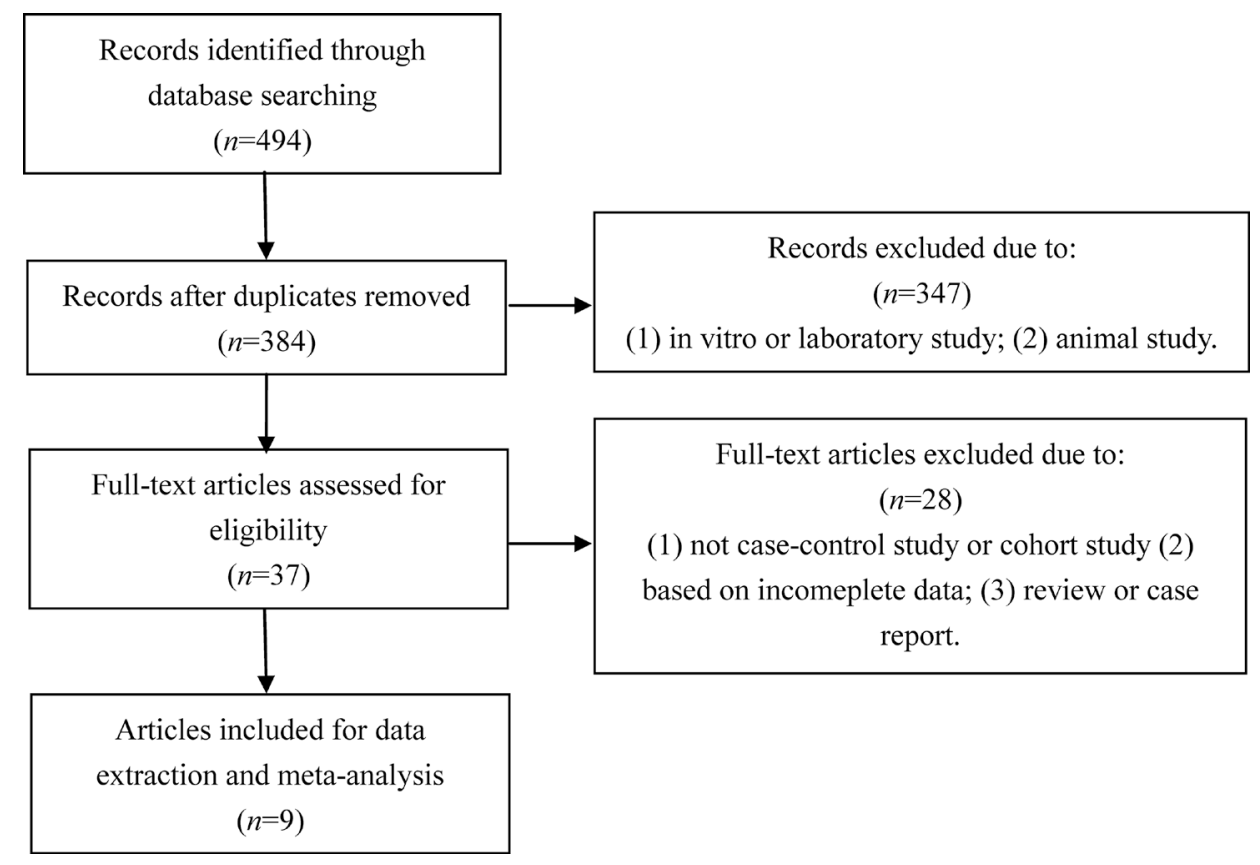

Figure 1: Flow chart of the study. 


\section{DISCUSSION}

Although little is know about the correlation of Se for HCC, several studies have shown that there is an inverse correlation between HCC risk and Se level. We performed the meta-analysis with the latest resouce on the correlation between HCC risk and Se level. Combining the results from 9 studies, which applied individual levels of Se measured in serum, blood or toenails, indicated that there was a significant high risk of HCC correlate with low levels of Se (Figure 2). As can be seen in Table 2, the pools OR for Se level in HCC patients in all studies was $-1.08(95 \% \mathrm{CI}=-0.136,-0.8)$ compare with the healthy controls. In the subgroup analysis by study design, race, sample collection, we found these factors significantly influnce the role of low Se level in incidence of HCC. Additionally, significant heterogeneity was found in subgroup analyses and might detract from the validity of the results. Thus, more research is needed to investigate the correlations between HCC risk and low Se level in Asian and the studies with blood collection.

Evidence indicated several mechanisms for $\mathrm{Se}$ antitumous effect. Actually, antioxidant properties of selenoproteins are relevant in protection from cancers [25]. Evidence from animal models and primary human hepatocytes implicate Se in liver cancer development
[1-4], whereas progressive cancer grade were correlated with decreasing Se concentrations in HCC tumor tissues [26]. Nataliya stated that in the case of HCC patients with low Se levels, Se supplementation could be considered for chemoprevention [2]. It is also showed a 50\% Se-induced reduction in HCC occurrence in China [27].

As far as we know, this is the first systematic review to investigate the correlation between Se levels with HCC in patients. However, the limitations of the present study must be considered. The reslut of the present study found a significant heterogeneity. Study design subgroup showed $\mathrm{I}^{2}$ value was decreased. The result suggested that the major source of the heterogeneity might be the study design. For the age subgroup analysis, the age groups did not match perfectly. We have use an age range of 20-60 years as "adult" and an range of older than 60 years as "older". However, most of the studies with ages ranging between 20-80 years in HCC patients. Thus, our finding is unlikely to be the result of unequal age ditribution. We were not able to investigate the effect of sex subgroups because of a lack of data. Additionally, Begg's tests results showed that there was no significant publication bias in this metaanalysis.

In conclusion, this meta-analysis supports an inverse correlation between Se level and the risk of HCC in humans. However, both epidemiological survey

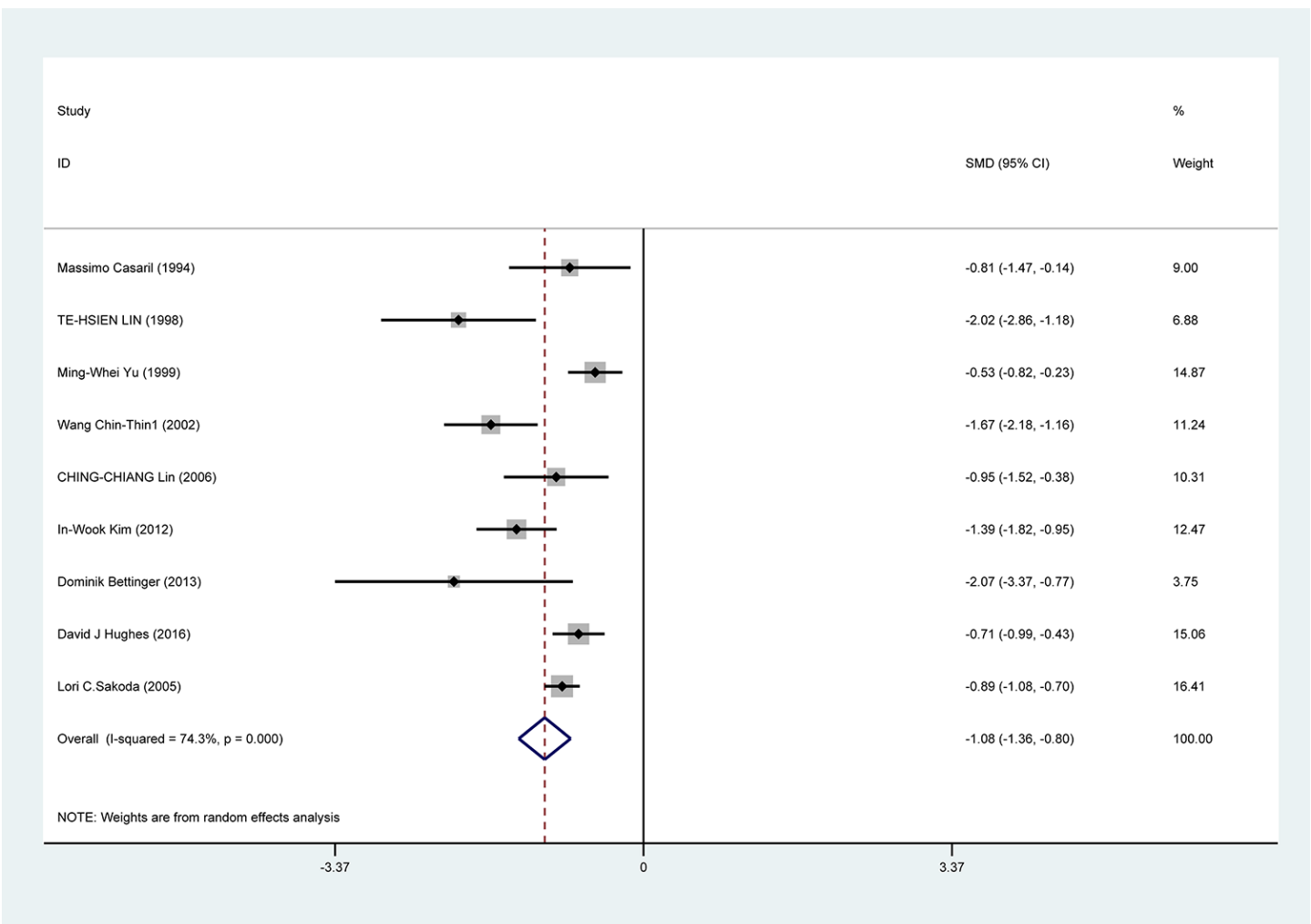

Figure 2: Forest plots for meta-analysis of the correlation of Se level with HCC risk. Square represents effect estimate of individual studies with their $95 \%$ confidence intervals. In this chart, studies are stored in order of years of publication and author's names, based on a random effects model. 


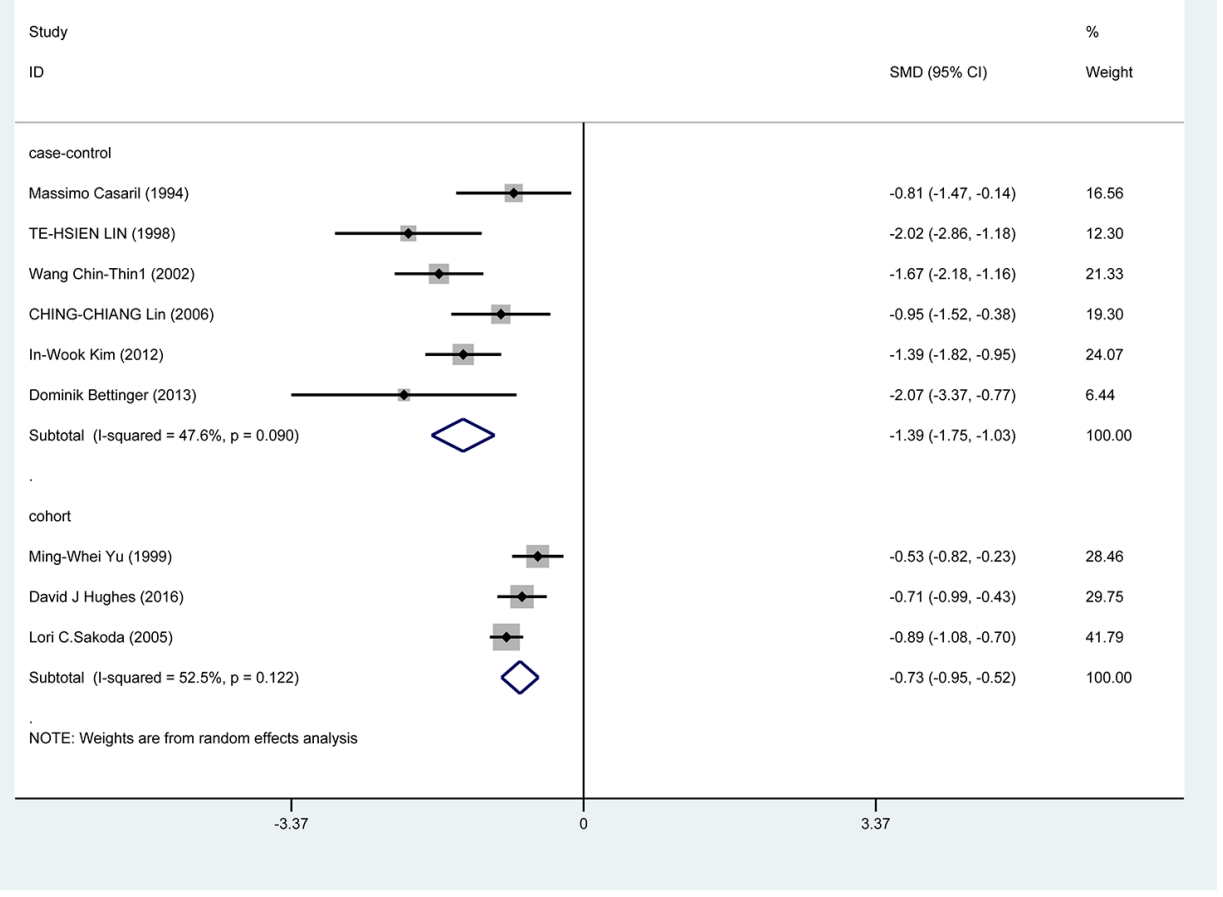

Figure 3: Forest plots for meta-analysis of in subgroups by study design in the correlation of Se level in with HCC risk. Square represents effect estimate of individual studies with their $95 \%$ confidence intervals. In this chart, studies are stored in order of years of publication and author's names, based on a random effects model..

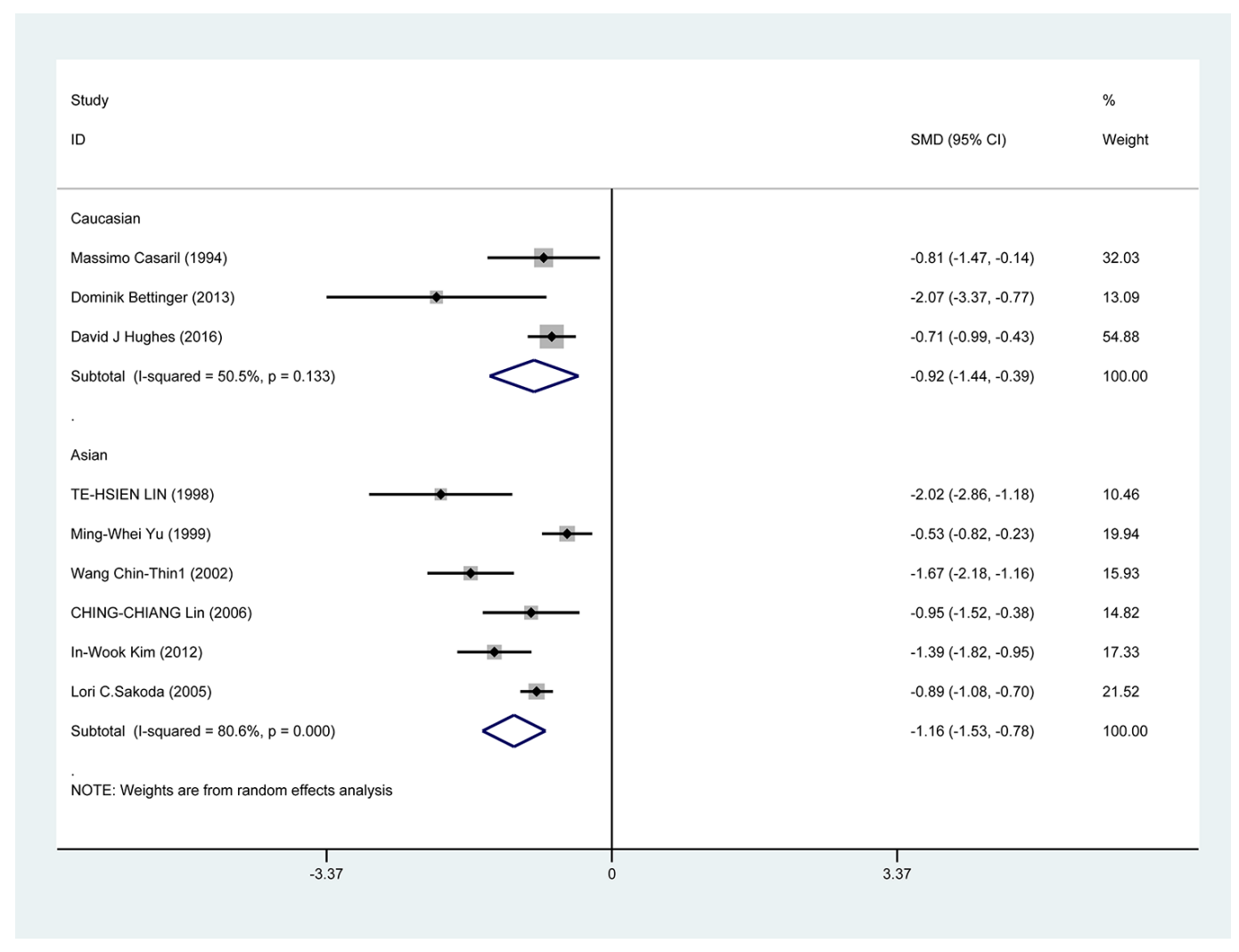

Figure 4: Forest plots for meta-analysis of in subgroups by race in the correlation of Se level in with HCC risk. Square represents effect estimate of individual studies with their $95 \%$ confidence intervals. In this chart, studies are stored in order of years of publication and author's names, based on a random effects model. 
Table 2: Results of this meta-analysis

\begin{tabular}{|c|c|c|c|c|c|c|}
\hline \multicolumn{5}{|c|}{ Association } & \multicolumn{2}{|c|}{ Heterogeneity } \\
\hline & Num & SMD $(95 \%$ CI $)$ & $P$ value & Model & $\mathrm{I}^{2}(\%)$ & $P$ value \\
\hline overall & 9 & $-1.08(-0.136,-0.08)$ & $P<0.001$ & $\mathrm{R}$ & 74.3 & $P<0.001$ \\
\hline \multicolumn{7}{|l|}{ Study design } \\
\hline case-control & 6 & $-1.388(-1.751,-1.026)$ & $P<0.001$ & $\mathrm{R}$ & 47.6 & $P=0.09$ \\
\hline cohort & 3 & $-0.733(-0.945,-0.520)$ & $P<0.001$ & $\mathrm{R}$ & 52.5 & $P=0.122$ \\
\hline \multicolumn{7}{|l|}{ Race } \\
\hline Caucasian & 3 & $-0.918(-1.443,-0.393)$ & $P<0.001$ & $\mathrm{R}$ & 50.5 & $P=0.133$ \\
\hline Asian & 6 & $-1.115(-1.526,-0.784)$ & $P<0.001$ & $\mathrm{R}$ & 80.6 & $P<0.001$ \\
\hline \multicolumn{7}{|c|}{ Sample collection } \\
\hline Serum & 3 & $-1.113(-1.472,-0.755)$ & $P<0.001$ & $\mathrm{R}$ & 23.5 & $P=0.27$ \\
\hline Blood & 5 & $-1.241(-1.795,-0.678)$ & $P<0.001$ & $\mathrm{R}$ & 84.7 & $P<0.001$ \\
\hline Toenail & 1 & $-0.889(-1.081,-0.697)$ & $P<0.001$ & $\mathrm{R}$ & 0 & $P<0.001$ \\
\hline
\end{tabular}

Num, number; SMD, standardized mean difference; CI, confidence intercal; R, randomeffects model.

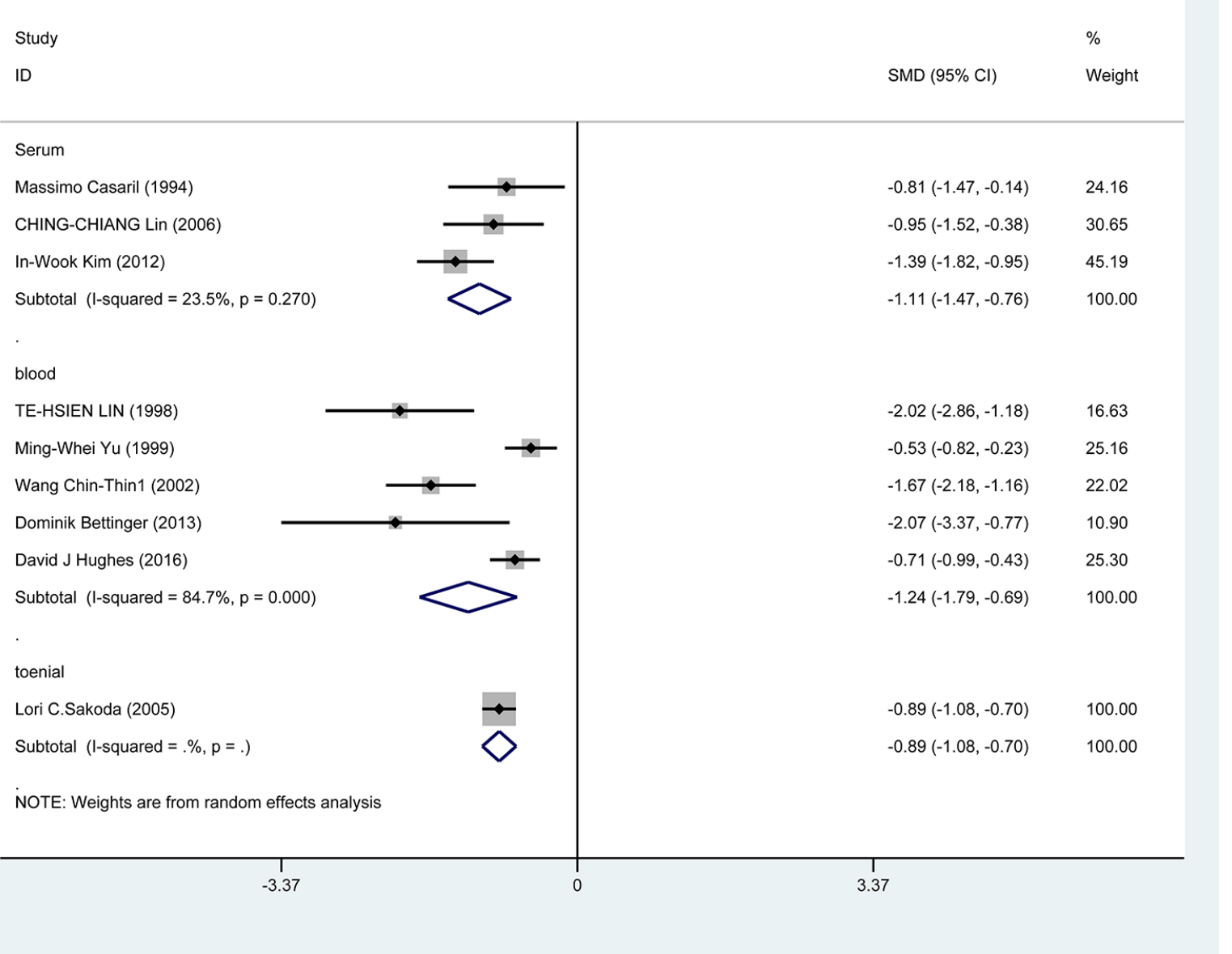

Figure 5: Forest plots for meta-analysis of in subgroups by collection in the correlation of Se level in with HCC risk. Square represents effect estimate of individual studies with their $95 \%$ confidence intervals. In this chart, studies are stored in order of years of publication and author's names, based on a random effects model. 
and biological research should be further conducted to illustrate and validate whether Se supplement is beneficial for prevention and treatment of HCC. The exact mechanism needs to be further investigated.

\section{MATERIALS AND METHODS}

\section{Search strategy}

Studies were identified by searching PubMed, EMBASE, web of science, Cochrane Library, Springer Link, Chinese National Knowledge Infrastructure (CNKI), and Chinese Biology Medicine (CBM) before August 2016, using the following Mesh terms: ("Liver Neoplasms" [MeSH] or "liver cancer" or "Hepatocellular Cancer" or "Hepatic Neoplasm") and ("selenium"or "Se"). Reference lists of all eligible studies were screened to identify potentially eligible studies. Emails were sent to the authors of identified studies for additional information if necessary.

\section{Selection criteria}

Studies included in this meta-analysis have to meet the following criteria: (1) human study; (2) case-control study or cohort study studying on correlation between Se and HCC; (3) all patients with the diagnosis of HCC confirmed by pathological or histological examination; (4) studies providing serum levels of Se for both subjects with HCC and healthy controls; (5) subjects with no other diseases and no drugs intake which might influence the levels of Se. Studies were excluded when they were: (1) in vitro or laboratory study; (2) animal study; (3) not casecontrol study or cohort study; (4) based on incomeplete data; (5) review or case report.

\section{Data extraction and assessment of study quality}

Data were independently extracted by two reviewers using a standardized data extraction form. Discrepancies were resolved by discussion and if consensus was not achieved the decision was made by all the reviewers. The following data was extracted from every article: first author, year of publication, study design, race, age and sex, sample size, years of follow-up, levels of Se and sample collection.

\section{Statistical analyses}

Statistical analysis was conducted by using STATA version 12. The correlation of Se level and HCC was estimated by SMD with 95\% CI. Both fixed and random effects models were assessed, but the latter was preferentially used when heterogeneity was detected. The $\mathrm{I}^{2}$ statistic was used to determine the level of heterogeneity potential sources of heterogeneity were explored using subgroup analysis to check the influence of the following determinants: study design, race and sample collection. Publication bias was explored Begg's Test. $P$ value less than 0.05 was considered statistically significant.

\section{ACKNOWLEGMENTS AND FUNDING}

This study was supported by the National Natural Science Foundation of China (31402267 to Z.Zhang), Heilongjiang Province Science Foundation for Youths (QC2014C015 to Z.Zhang), Heilongjiang Postdoctoral Fund (LBH-Z13028 to Z.Zhang), Foundation for Young Talents in Higher Education of Heilongjiang, China (UNPYSCT-2015009 to Z.Zhang), "Young Talents" Project of Northeast Agricultural University (14QC20 to Z.Zhang) and International (Regional) Cooperation and Exchange Projects of the National Natural Science Foundation of China (31320103920 to S.Xu).

\section{CONFLICTS OF INTEREST}

The authors declare no conflicts of interest.

\section{REFERENCES}

1. Liu JG, Zhao HJ, Liu YJ, Liu YW, Wang XL. Effect of two selenium sources on hepatocarcinogenesis and several angiogenic cytokines in diethylnitrosamine-induced hepatocarcinoma rats. J Trace Elem Med Biol. 2012; 26: 255-61.

2. Rohr-Udilova N, Sieghart W, Eferl R, Stoiber D, Björkhem-Bergman L, Eriksson LC, Stolze K, Hayden H, Keppler B, Sagmeister S, Grasl-Kraupp B, Schulte-Hermann R, Peck-Radosavljevic M. Antagonistic effects of selenium and lipid peroxides on growth control in early hepatocellular carcinoma. Hepatology. 2012; 55: 1112-21.

3. Kasaikina MV, Turanov AA, Avanesov A, Schweizer U, Seeher S, Bronson RT, Novoselov SN, Carlson BA, Hatfield DL, Gladyshev VN. Contrasting roles of dietary selenium and selenoproteins in chemically induced hepatocarcinogenesis. Carcinogenesis. 2013; 34: 1089-95.

4. Moustafa ME, Carlson BA, Anver MR, Bobe G, Zhong N, Ward JM, Perella CM, Hoffmann VJ, Rogers K, Combs GF, Schweizer U, Merlino G, Gladyshev VN, et al. Selenium and selenoprotein deficiencies induce widespread pyogranuloma formation in mice, while high levels of dietary selenium decrease liver tumor size driven by TGF $\alpha$. PLoS One. 2013; 8:e57389.

5. Maki A, Kono H, Gupta M, Asakawa M, Suzuki T, Matsuda M, Fujii H, Rusyn I. Predictive power of biomarkers of oxidative stress and inflammation in patients with hepatitis C virus-associated hepatocellular carcinoma. Ann Surg Oncol. 2007; 14:1182-90. 
6. Konishi M, Iwasa M, Araki J, Kobayashi Y, Katsuki A, Sumida Y, Nakagawa N, Kojima Y, Watanabe S, Adachi Y, Kaito M. Increased lipid peroxidation in patients with non-alcoholic fatty liver disease and chronic hepatitis $\mathrm{C}$ as measured by the plasma level of 8-isoprostane. J Gastroenterol Hepatol. 2006; 21: 1821-5.

7. Novotny L, Rauko P, Kombian SB, Edafiogho IO. Selenium as a chemoprotective anti-cancer agent: reality or wishful thinking. Neoplasma. 2010; 57:383-91.

8. Gong HY, He JG, Li BS. Meta-analysis of the association between selenium and gastric cancer risk. Oncotarget. 2016; 7:15600-5. doi: 10.18632/oncotarget.7205.

9. Yao HD, Wu Q, Zhang ZW, Li S, Wang XL, Lei XG, $\mathrm{Xu}$ SW. Selenoprotein W serves as an antioxidant in chicken myoblasts. Biochim Biophys Acta. 2013; 1830:3112-20.

10. Yao HD, Wu Q, Zhang ZW, Zhang JL, Li S, Huang JQ, Ren FZ, Xu SW, Wang XL, Lei XG. Gene expression of endoplasmic reticulum resident selenoproteins correlates with apoptosis in various muscles of se-deficient chicks. J Nutr. 2013; 143:613-9.

11. Chin-Thin W, Wei-Tun C, Tzu-Ming P, Ren-Tse W. Blood concentrations of selenium, zinc, iron, copper and calcium in patients with hepatocellular carcinoma. Clin Chem Lab Med. 2002; 40:1118-22.

12. Kim IW, Bae SM, Kim YW, Liu HB, Bae SH, Choi JY, Yoon SK, Chaturvedi PK, Battogtokh G, Ahn WS. Serum selenium levels in Korean hepatoma patients. Biol Trace Elem Res. 2012; 148: 25-31.

13. Tashiro H, Kawamoto T, Okubo T, Koide O. Variation in the distribution of trace elements in hepatoma. Biol Trace Elem Res. 2003; 95: 49-63.

14. Kolachi NF, Kazi TG, Afridi HI, Kazi NG, Khan S. Investigation of essential trace and toxic elements in biological samples (blood, serum and scalp hair) of liver cirrhotic/cancer female patients before and after mineral supplementation. Clin Nutr. 2012; 31: 967-73.

15. Yu SY, Zhu YJ, Li WG, Huang QS, Huang CZ, Zhang QN, Hou C. A preliminary report on the intervention trials of primary liver cancer in high-risk populations with nutritional supplementation of selenium in China. Biol Trace Elem Res. 1991; 29: 289-94.

16. Casaril M, Corso F, Bassi A, Capra F, Gabrielli GB, Stanzial AM, Nicoli N, Corrocher R. Decreased activity of scavenger enzymes in human hepatocellular carcinoma, but not in liver metastases. Int J Clin Lab Res. 1994; 24: 94-7.

17. Lin TH, Tseng WC, Cheng SY. Direct determination of selenium in human blood plasma and seminal plasma by graphite furnace atomic absorption spectrophotometry and clinical application. Biol Trace Elem Res. 1998; 64:133-49.
18. Kazi TG, Kolachi NF, Afridi HI, Kazi NG, Sirajuddin, Naeemullah, Arain SS. Effects of mineral supplementation on liver cirrhotic/cancer male patients. Biol Trace Elem Res. 2012; 150:81-90.

19. Yu MW, Horng IS, Hsu KH, Chiang YC, Liaw YF, Chen CJ. Plasma selenium levels and risk of hepatocellular carcinoma among men with chronic hepatitis virus infection. Am J Epidemiol. 1999; 150:367-74.

20. Bettinger D, Schultheiss M, Hennecke N, Panther E, Knüppel E, Blum HE, Thimme R, Spangenberg HC Selenium levels in patients with hepatitis $\mathrm{C}$ virus-related chronic hepatitis, liver cirrhosis, and hepatocellular carcinoma: a pilot study. Hepatology. 2013; 57:2543-4.

21. Sakoda LC, Graubard BI, Evans AA, London WT, Lin WY, Shen FM, McGlynn KA. Toenail selenium and risk of hepatocellular carcinoma mortality in Haimen City, China. Int J Cancer. 2005; 115:618-24.

22. Yu SY, Zhu YJ, Li WG. Protective role of selenium against hepatitis B virus and primary liver cancer in Qidong. Biol Trace Elem Res. 1997; 56:117-24.

23. Lin CC, Huang JF, Tsai LY, Huang YL. Selenium, iron, copper, and zinc levels and copper-to-zinc ratios in serum of patients at different stages of viral hepatic diseases. Biol Trace Elem Res. 2006; 109:15-24.

24. Hughes DJ, Duarte-Salles T, Hybsier S, Trichopoulou A, Stepien M, Aleksandrova K, Overvad K, Tjønneland A, Olsen A, Affret A, Fagherazzi G, BoutronRuault MC, Katzke V, et al. Prediagnostic selenium status and hepatobiliary cancer risk in the European Prospective Investigation into Cancer and Nutrition cohort. Am J Clin Nutr. 2016; 104:406-14.

25. Gorozhanskaia ÉG, Sviridova SP, Dobrovol'skaia MM, Zybrikhina GN, ShR K. [Selenium and oxidative stress in cancer patients]. Biomed Khim. 2013; 59:550-62.

26. DI SM, Volpe MG, Colonna G, Nazzaro M, Polimeno M, Scala S, Castello G, Costantini S. A possible predictive marker of progression for hepatocellular carcinoma. Oncol Lett. 2011; 2:1247-1251.

27. Li W, Zhu Y, Yan X, Zhang Q, Li X, Ni Z, Shen Z, Yao H, Zhu J [The prevention of primary liver cancer by selenium in high risk populations]. Zhonghua Yu Fang Yi Xue Za Zhi. 2000; 34:336-8. 